\title{
EFFICIENCY ESTIMATION FOR PERMANENT MAGNETS OF SYNCHRONOUS WIND GENERATORS
}

\author{
A. Serebryakov, N. Levin, A. Sokolov, E. Kamolins \\ Riga Technical University \\ 1 Kalku Str., Riga, LV-1658, LATVIA \\ e-mail: edmunds.kamolins@rtu.lv
}

\begin{abstract}
Application of wind generators opens wide possibilities for raising the efficiency of low- and medium-power wind generators (WGs). The mass of generators in the proposed version is smaller, their reliability higher, while maintenance costs are lower. At the same time, the use of high-energy permanent magnets in generators of enhanced power comes up against some obstacles, which can be overcome through proper orientation of magnetization at creation of a magnetic field in the airgap of electrical machine. In this regard, it might be preferable to use magnets with indirect action on the airgap instead of those with direct action. A convincing example of the former variant is a generator with tangentially oriented magnetization of permanent magnets. In the work, an attempt is done to prove the advantages of such installation in modern low- and medium-power WGs.
\end{abstract}

Keywords: wind generator (WG), permanent magnets, tangential orientation, efficiency, reliability.

\section{INTRODUCTION}

Widening the scope of application of permanent magnets in low- and medium-power wind generators (WGs), their constant perfection, and, which is of prime importance, their being ecological - all entirely meet the requirements of today [1-5].

The main direction towards perfection of a low- and medium-power WG is to raise the utilization factor of its installed capacity and to reduce its maintenance costs.

In this process, of importance is a generator as the main element for conversion of wind energy into electrical one. Its functions are not only to perform a highly efficient energy conversion in a wide range of rotational speeds but also to exclude detrimental effects such as hard start-up of a wind installation. The delayed starting-up at low wind velocities, reduced rotational speed at a strong wind or its gusts as well as at sudden changes of its direction - all this sets limits on the use of installed capacities. Under these conditions the WG is to become a matching link between the source of energy (wind) and its receiver (consumer). In this case the 
WG performance determines the effectiveness of the whole energy conversion process.

It should be noted that the use of permanent magnets (instead of electromagnetic excitation) notably complicates the WG performance in the function of a smoothing link. To an extent, in this case the control over electric machine seems to be worse.

Obviously, if permanent magnets were the cause of worsened coordination in the work of a "wind-turbine-generator-receiver of electric energy" chain, it is these magnets that are to restore the normal work in this chain.

At direct action of permanent magnets on the airgap in an electric machine - i.e. at immediate creation of magnetic field - the control over operation of the generator is often lost: it can either excite electro-magnetic modes or - at extreme situations connected with thermal overloads of magnets - to lose its basic qualities in the energy conversion process.

In this regard, generators with tangentially directed magnetization of its magnets can be more convenient from the viewpoint of interaction with airgap as the main receptacle of electro-magnetic energy participating in the conversion process $[6,7]$.

Therefore, the indirect action of permanent magnets' MMF on the airgap might turn out to be more stable and effective than a direct one.

In this connection we will consider the advantages and disadvantages of the magnets with tangentially orientated magnetization when used in low- and medium-power WGs.

\section{ADVANTAGES AND DISADVANTAGES OF WIND GENERATORS WITH TANGENTIALLY ORIENTED MAGNETIZATION OF MAGNETS}

Figure 1 illustrates the circuit design for setting up the permanent magnets that are oriented tangentially with respect to the airgap. In the figure it is seen that the magnetic flux $\Phi$ in magnet 3 placed between two cores (teeth) of the rotor is oriented tangentially with respect to the outer cylindrical surface of rotor. The magnetic flux - when leaving the magnet - "turns around" in the direction to airgap. As it takes place, above the pole of magneto-soft steel the magnetic fluxes of two magnets abut with the core are added up.

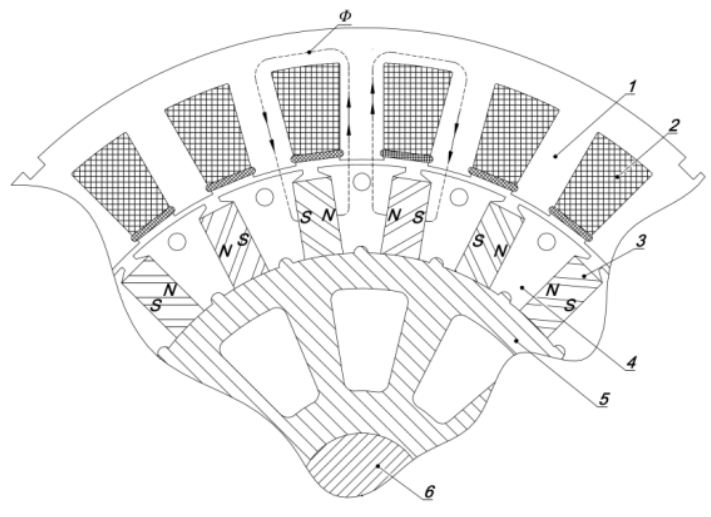

Fig. 1. Fragment of the generator design with tangentially oriented magnets:

1 - stator tooth;

2 - slot with armature winding;

3 - permanent magnet;

4 - rotor core;

5 - rotor sleeve (nonmagnetic);

6 - shaft. 
In turn, Fig. 2 shows a circuit design for setting up the magnets with direct action on the airgap. In this design, magnetic flux $\Phi$ at its leaving the magnet immediately approaches the airgap without changing its direction.

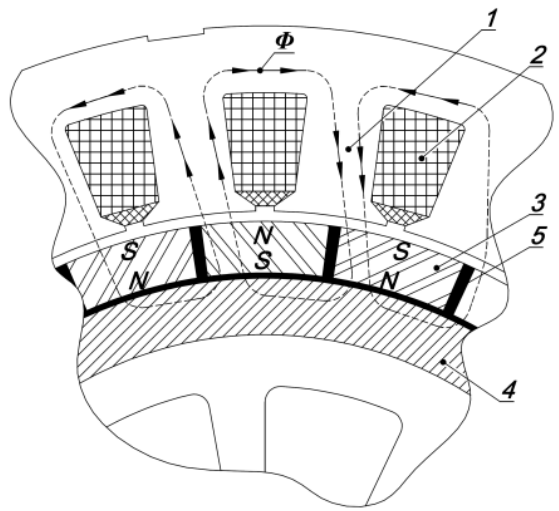

Fig. 2. Fragment of the generator design with a direct action of magnets on airgap:

1 - stator tooth;

2 - armature winding;

3 - permanent magnet;

4 - rotor sleeve (magnetic conductive);

5 - adhesive bonding magnets with sleeve

When comparing these two ways of magnets' setting up, one can see at once the following disadvantages of the indirect formation of magnetic field in the airgap:

$>$ more complicated and, consequently, more expensive design of the rotor;

$>$ possible appearance of additional non-magnetic spans (other than the airgap) in the path of the magnetic flux;

$>$ closer position of cores and magnets with respect to the shaft of electrical machine, which can result in increased leakage fluxes;

$>$ appearance of additional spans in the magnetic circuit for creation of leakage fluxes (a part of the slot above the magnet as well as magnets' ends becoming too close when approaching the shaft).

All the listed disadvantages are clearly seen, and they can be estimated only in comparison with potential advantages which would be evident at more thorough analysis of the electric machine's designs.

At the same time, it could be pointed out that under consideration here will be only the synchronous generator whose armature winding is made concentrated, in the form of toothed coil as providing a higher specific power of the electric machine $[8,9]$.

Of all advantages peculiar to the synchronous generators with tangentially oriented magnetization of permanent magnets the most valuable is that they provide the best adaptation of these magnets to the tooth zone and to the magnetic circuit as a whole, together with the armature winding - at any their design.

Indeed, if the magnet adjoins immediately the airgap, the stator slots cannot be made open or even half-open, since in this case the magnet is not fully utilized and is subject to the action of variable MMF reaction. In this case a considerable part of the magnet does not create any magnetic flux since it is positioned oppositely with respect to the stator slot, while its other part that is opposite to the tooth tip does not compensate for the loss thus created.

Quite another situation arises at indirect action of the magnet on the airgap. Here a magneto-soft core between two magnets captures all the available magnetic 
flux and, practically without loss, passes it into the airgap - just to its part that at a given time moment is opposite to the stator tooth.

An important advantage of the magnets with tangentially oriented magnetization as used in wind generators is the possibility to construct optimally the tooth zone - i.e. with the maximum utilization of the magnetic flux that could be created by a permanent magnet.

Figure 3 shows the version with the width of the open slot being equal to that of a tooth width, whereas the width of the magnet - to that of tooth pitch $(\alpha=0.85-0.90)$. In this case, as follows from Fig. 3, the magnetic flux linked with the coil of armature winding is $\Psi=w_{k} \Phi$, where $w_{k}$ is the number of turns in the coil, $\Phi$ is a variable value (the magnetic flux) whose time dependence shape is trapezoidal, with equal time intervals for rise and fall and with a double time value at an invariable magnetic-flux linkage $\left(\Delta t_{1}=\Delta t_{3}=\Delta t_{2} / 2\right)$. In this case the amplitude of the first harmonic is [10]:

$$
\Phi_{1}=\frac{8 \sqrt{2}}{\pi^{2}} \Phi_{m}=1.15 \Phi_{m},
$$

i.e. exceeding by $15 \%$ the maximum magnetic flux created by the magnets (since in our case there are two magnets participating in the process).

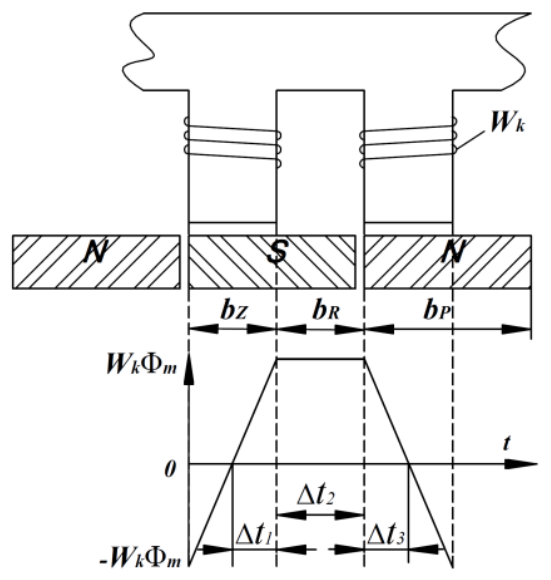

Fig. 3. The shape of flux linkage with coil $W_{k}$ at $b_{Z}=b_{R}=\frac{1}{2} b_{P}$ (open slots).

Magnetic flux $\Phi_{1}=1.15 \Phi_{m}$ at $\Delta t_{1}=\Delta t_{3}=\frac{\Delta t_{2}}{2}$.

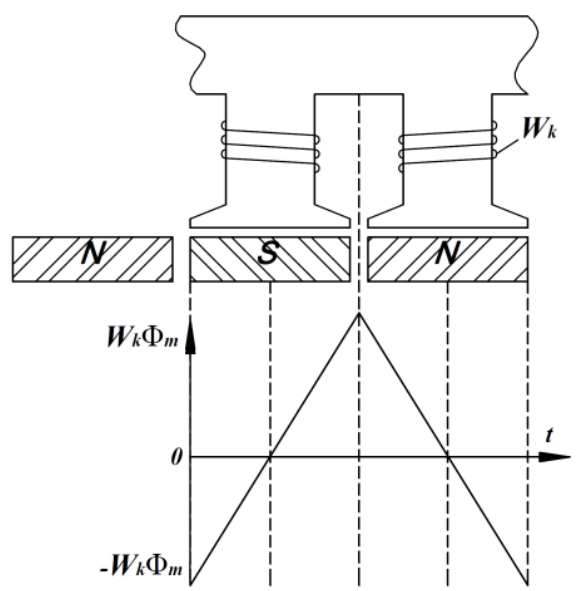

Fig. 4. The shape of flux linkage with coil $W_{k}$ at $b_{Z}=b_{R}$ (closed slots).

Magnetic flux $\Phi_{1}=0.81 \Phi_{m}$.

In turn, at a closed stator's slot (a recommended version for direct action of the magnet on airgap, see Fig. 4) the dependence shape of magnetic flux variations is triangular, at which the first harmonic of the flux will be:

$$
\Phi_{1}=\frac{8}{\pi^{2}} \Phi_{m}=0.81 \Phi_{m} .
$$


Comparison of magnetic fluxes according to Eqs. (1) and (2) shows that at indirect action of the magnet on airgap the first harmonic is practically by $35 \%$ greater than possible for a given magnet in the former (direct) case. Therefore, a real opportunity exists to reduce correspondingly the mass and size of the electrical machine.

In addition, the use of magnets with tangentially oriented magnetization gives two more advantages: higher manufacturability and reliability, since the coils of an armature winding for medium-power WGs can be made preliminarily using a special machine; this would provide a higher factor of filling the slot(s) by copper and a better quality of the armature winding as a whole.

An important virtue of the version with tangentially oriented magnetization of magnets is also a higher degree of their thermal and mechanical protection. The increased thermal protection is provided by a more distant location of magnets from the source of heat and by loss-free operation of these magnets owing to their being screened from varying magnetic field by the ferromagnetic cores. The better thermal protection of magnets makes it possible to choose among those with lower allowable temperature at the stage of making WGs, which, therefore, will be cheaper and with better energy indices. The last but not least - they will also be more reliable at work.

The asset that deserves attention to the described version is the possibility to reach the magnetic induction in the airgap that would exceed its residual value for the magnet-hard materials used. Therefore, the optimal form of the tooth zone can be achieved via the open slots; besides, this allows applying in particular cases cheaper and more reliable low-energy magnets (e.g. of ferrite-barium or ferritestrontium $[8,9,11])$.

The creation in the airgap of strong magnetic fields is an important prerequisite for designing WGs with a high specific torque, which would thus be lowspeed and powerful electric machines without mechanical multipliers.

We have not to ignore such an advantage as their higher maintainability, which is achieved due to the absence of adhesive joints between the magnets and the ferromagnetic cores or other elements of design. The absence of such joints also contributes to achievement of higher reliability, since at fast temperature rise not only the efficiency of magnets is lower, but also the strength characteristics of their adhesive joints are impaired to an extent.

A major advantage of the WG version under consideration - i.e. with tangentially oriented magnetization of magnets separated from the airgap by ferromagnetic elements of the core - lies in the possibility to reduce losses not only for the magnets that can in this case not be partially re-magnetized, but also for other machine's elements that are subject to the action of higher harmonics of the magnetic flux.

Not the least advantage of a wind generator with the tangential orientation of its magnets is a lower sensitivity to deviations in their parameters with respect to each other. This is achieved through closer interaction of these magnets, since in this version two magnets at once adjoin the pole core, each of them in turn being connected with the third, fourth, etc. magnets.

A substantial benefit that could be derived from the use of generators with tangential orientation of magnets is the possibility to make these latter with an 
uneven airgap (increased at the pole boundaries). This allows for elimination of the higher harmonics of magnetic flux, thus reducing the iron losses and the core mass. At the cost of uneven airgap it would also be possible to damp the torque pulsations without resorting to such a difficult-to-realize technical solution as skewing the stator or rotor slots.

Having pointed up all the advantages of this WG version, we also have to mention its disadvantages (partially described above). These latter are however not so much important and can be easily compensated by more weighty advantages.

At the same time, we cannot pass over in silence such an important (at first sight) demerit as rather strong impact exerted by the transversal armature reaction of a generator on its load-carrying capacity, which as if could rise (judging from the results of its action) due to the presence of magneto-soft cores arranged between two magnets.

However, it should be noted that at the optimally chosen structure of the tooth zone (i.e. when the stator slot is open and $Z_{s}<2 p$ ) the influence of the transversal armature reaction weakens and becomes comparable with the action of slot and front magnetic leakages. In this case a slot of the stator becomes as wide as its pole, so is not overlapped by the rotor's pole.

An effective measure against the transversal armature reaction is making uneven the airgap under the pole: the greatest near the edges and the smallest under the middle. In such a design the magnetic resistance along the transversal axis $X_{q}$ will not differ much from $X_{d}$ and will mainly reduce to the magnetic leakage resistance.

As a disadvantage that is sometimes pointed out is that in a generator with tangentially oriented magnets the flux is passed through two airgaps, which implies that the magnet must be more massive. At the same time, this magnet could be made half as wide since in the formation of magnetic flux two magnets are participating, which means that this disadvantage turns out to be a new advantage.

Therefore, the design of generators with tangentially oriented magnets is devoid of serious flaws while possesses quite a number of advantages.

\section{EXPERIMENTAL VERIFICATION OF THE PROPOSED WG VERSION}

The major advantage at the use of permanent magnets with tangentially oriented magnetization in low- and medium-power WGs is a considerable rise (up to $35 \%$ ) in specific power (electro-magnetic torque), and, consequently, a smaller mass, which means a lower cost of magnets.

In support of the mentioned and, possibly, some other advantages a test prototypal wind generator was made, which had the following parameters:

- useful power $1500 \mathrm{~W}$;

- rotational speed $300 \mathrm{~min}^{-1}$;

- output rectified voltage $250 \mathrm{~V}$;

- rectified load current $6 \mathrm{~A}$;

- mass of generator $\leq 30 \mathrm{~kg}$.

In Fig. 5 the calculated and built-up test prototype of the generator is depicted. Figures 6, 7 show, respectively, the stator with an armature winding and 
the rotor with permanent magnets of magneto-hard material $(\mathrm{NdFeB})$ with the following characteristics: induction $B_{r}=0.9 T$; coercive force $H_{C}=700 \mathrm{kA} / \mathrm{m}$.

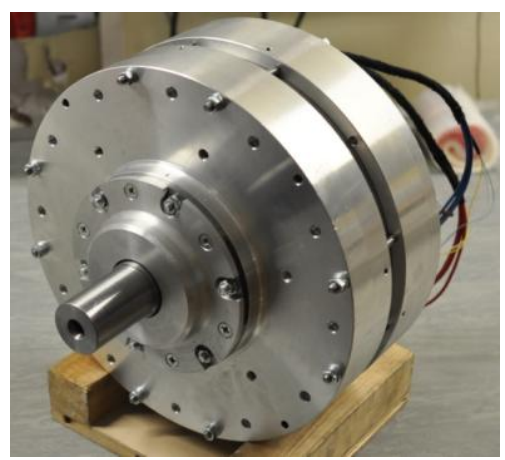

Fig. 5. Test prototype of the generator.

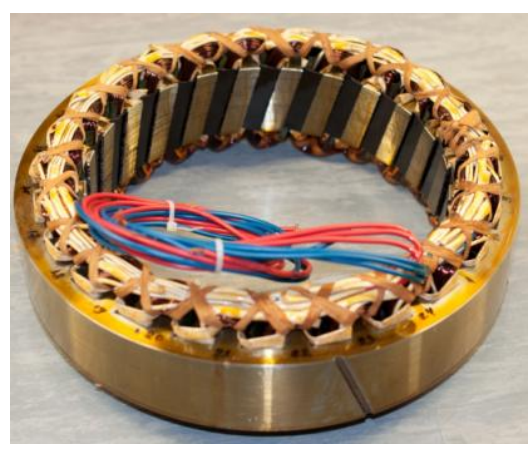

Fig. 6. The stator with armature winding.

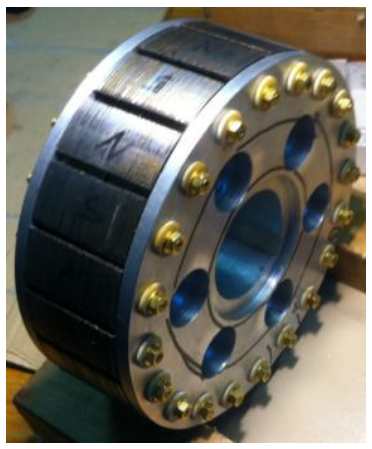

Fig. 7. The rotor with permanent magnets of magneto-hard material (NdFeB).

It should be noted that the magneto-hard material used was not from the best ones; the choice was dictated by the necessity to decrease the cost of making the prototype.

The prototype was tested on the engine test bed. The external characteristics of generator are presented in Fig. 8. In compliance with these characteristics and the RFP (request for proposal) the generator at its rotational speed of $300 \mathrm{~min}^{-1}$ is to develop the power $P_{N}=1600 \mathrm{~W}$, which at the mass of generator being $29.0 \mathrm{~kg}$ determines its specific power as

$$
P_{s p}=\frac{P_{N}}{G_{g}}=\frac{1600}{29}=55.1 \mathrm{~W} / \mathrm{kg},
$$

and, respectively, the specific torque $M_{s p}$ as

$$
M_{s p}=\frac{P_{N}}{\frac{2 \pi n}{60} G_{g}}=\frac{1600}{\frac{2 \cdot 3.14 \cdot 300}{60} \cdot 29}=1.76 \mathrm{Nm} / \mathrm{kg} .
$$




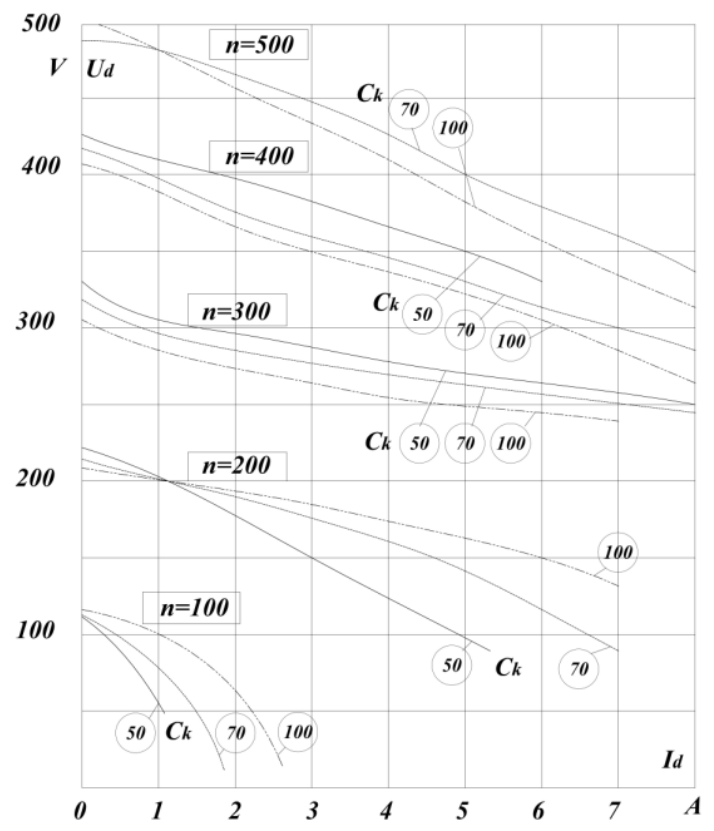

Fig. 8. The external characteristics of tested generator.

For comparison, one of the world's best and widely advertised wind generators (GL-PMG-1000, GINLONA Co., China, made according to the scheme of Fig. 2 with radial orientation of $\mathrm{NdFeB}$ permanent magnets) develops at the rated rotational speed of $450 \mathrm{~min}^{-1}$ the power $P_{N}=1000 \mathrm{~W}$, and has the mass of $16.7 \mathrm{~kg}$. Its specific power is:

$$
P_{s p}=\frac{P_{N}}{G_{g}}=\frac{1000}{16.7}=59.9 \mathrm{~W} / \mathrm{kg},
$$

though at a higher rotational speed $\left(450 \mathrm{~min}^{-1}\right.$ instead of $\left.300 \mathrm{~min}^{-1}\right)$.

For comparison, the parameters of the Chinese generator operating at 300 $\min ^{-1}$ would be: nominal power $P_{N}=600 \mathrm{~W}$ (determined experimentally), and the specific power $P_{s p}=36 \mathrm{~W} / \mathrm{kg}$. The specific torque $M_{s p}$ would be:

$$
M_{s p}=\frac{P_{N}}{\frac{2 \pi n}{60} G_{g}}=\frac{1000}{\frac{2 \cdot 3.14 \cdot 450}{60} \cdot 16.7}=1.33 \mathrm{Nm} / \mathrm{kg},
$$

which is 1.33 times (33\%) worse than that of the experimental prototype with tangentially oriented magnets.

If we take into account that the material used for permanent magnets was far enough from the best, it can be stated with certainty that the proposed low- and medium-power WG with tangential orientation of magnets as to their magnetization possesses significant advantages.

It is important that its other indices are not worse: for example, the startingup moment at a concentrated armature winding was $M_{0}=1 N \cdot m$, i.e. with respect to the nominal moment of the generator being 


$$
M_{N}=\frac{P_{N}}{\frac{2 \pi n}{60}}=\frac{1600}{\frac{2 \cdot 3.14 \cdot 300}{60}}=51 \mathrm{~N} \cdot \mathrm{m}
$$

makes up 2\%:

$$
M_{0} \%=\frac{M_{0}}{M_{N}} 100 \%=\frac{1}{51} 100 \%=2 \%,
$$

while these parameters for the Chinese generator are:

$$
\begin{aligned}
& M_{N}=\frac{P_{N}}{\frac{2 \pi n}{60}}=\frac{1000}{\frac{2 \cdot 3.14 \cdot 450}{60}}=21 \mathrm{~N} \cdot \mathrm{m}, \\
& M_{0} \%=\frac{M_{0}}{M_{N}} 100 \%=\frac{0.5}{21} 100 \%=2.9 \%,
\end{aligned}
$$

The efficiency of the test prototypal generator was $\eta=86 \%$, and of the other generator $-\eta=67 \%$ (determined by us experimentally).

Above (in Fig. 8) the external characteristics of our generator are presented for different values of the corrective capacitance connected in series into the armature circuit.

It should be noted that the connection of the corrective capacitance opens an opportunity of matching better the characteristics of a WG with those of wind turbine, thus achieving more full utilization of the installed capacity of this generator. The use of such corrective capacitance allows raising additionally the nominal power up to $1670 \mathrm{~W}$.

It was also proved that the use of permanent magnets tangentially oriented in magnetization does not pose any stringent requirements as to their thermal stability. Heating the magnets in the prototypal generator during a long-lasting operation under nominal conditions did not exceed $70^{\circ} \mathrm{C}$ with natural cooling.

\section{CONCLUSIONS}

Having analyzed the advantages and disadvantages of the use in low- and medium-power wind generators of permanent magnets tangentially oriented in magnetization we can formulate the following conclusions:

1. The tangential orientation of permanent magnets in magnetization allows the use of open slots on the stator, thus simplifying the design, improving the performance of the armature winding and forming the variations in magnetic-flux linkage according to the sine law; this will heighten the specific power and the specific moment by $30-35 \%$.

2. An opportunity arises to increase the energy return of the permanent magnets and decrease their mass, and, if necessary, to apply cheaper and more reliable low-energy permanent magnets - for example, ferrite-barium or ferritestrontium ones. 
3. The proposed setting-up of the magnets allows for improvement of the reliability and maintainability of the generators by eliminating the adhesive joints as well as facilitating the operational conditions for the permanent magnets by creating for them a more strong mechanical protection and better conditions of functioning.

\title{
ACKNOWLEDGEMENT
}

This work was supported in part by the ERAF project No. 2010/0215/2DP/ 2.1.1.1.0/10/APIA/VIAA/039, "Development of a slow-speed power generator for wind turbines".

\section{REFERENCES}

1. European Commission Directorate. European energy and transport. http://ec.europa.eu/dgs/energy_transport/figures/trends_2030/

2. Baranovs, O., et al. (2005). Report on the Latvian economic development. http://em.gov.lv/em/2nd/?id=32240\&cat=621 (in Latvian).

3. Twedell, J., \& Weir, T. (2003). Renewable Energy Resources. NY: Taylor \& Francis, p. 624.

4. Dirba, J., Levin, N., \& Pugachev, V. (2006). Electromechanical Converters of Wind Energy. Riga: RTU, p. 312 (in Latvian).

5. Alekseev, A. (1958). Design of the Electrical Machines. Leningrad: Gosenergoizdat, p. 428 (in Russian).

6. Boot D. A. (1990). Brushless Electrical Machines. Moscow: High School, p. 416 (in Russian).

7. Levin, N., Kamolins, E., \& Vitolina. S. (2011). Brushless Electrical Machines. Riga: RTU, p. 276 (in Latvian).

8. Levin, N., \& Serebryakov, A. (1991). Inductor generators in low-power wind applications. Moscow: Energoatomizdat, p. 53-55 (in Russian).

9. Levin, N., Pugachev, V., \& Orlova, S. (2012). Direct-drive contactless wind generator with concentrated winding. Latv. J. Phys. Tech. Sci., 49 (4), 14-20.

10. Bronstein I., \& Semendaev K. (1948). Handbook of mathematics for engineers and university students. M.-L.: OGIZ, p. 556 (in Russian).

11. Serebryakov, A., Levin, N., \& Sokolov, A. (2012). Efficiency improvement of directdriven synchronous generators with excitation from strontium-ferrite permanent magnets. Latv. J. Phys. Tech. Sci., 49 (4), p. 3-13.

\section{PASTĀVĪGO MAGNĒTU IZMANTOŠANAS EFEKTIVITĀTE SINHRONAJOS VĒJĢENERATOROS}

\author{
A. Serebrjakovs, N. Levins, A. Sokolovs, E. Kamoliņ̌s \\ Kopsavilkums
}

Pastāvīgo magnētu pielietošana vējǵeneratoros paver plašas iespējas mazas un vidējas jaudas vēja enerḡētisko iekārtu (VEI) efektivitātes paaugstināšanai. Turklāt samazinās ǵeneratoru masa, palielinās drošums, samazinās ekspluatācijas izmaksas. Tomēr, izmantojot augsti energீêtiskos pastāvīgos magnētus ǵeneratoros 
ar paaugstinātu jaudu, rodas virkne problēmu, kuras sekmīgi iespējams pārvarēt, ja pareizi izvieto magnētus pēc to orientācijas, radot magnētisko lauku elektriskās mašīnas gaisa spraugā.

Darbā ir mēgināâts pierādīt, ka eksistē būtiskas priekšrocības mazas un vidējas jaudas vējğeneratoros, ja pastāvīgie magnēti tiek magnetizēti tangenciāli attiecībā pret gaisa spraugu.

17.01.2014. 